\title{
CONSORCIAÇÃO DE PLANTAS DE COBERTURA ANTECEDENDO O MILHO EM PLANTIO DIRETO. II - NITROGÊNIO ACUMULADO PELO MILHO E PRODUTIVIDADE DE GRÃOS(1)
}

\author{
S. J . GIACOMINI(2), C. AITA(3), I. C. CHIAPINOTTO(4), \\ A. P. HÜBNER ${ }^{(2)}$, M. G. MARQUES ${ }^{(5)} \&$ F. CADORE ${ }^{(6)}$
}

\begin{abstract}
RESUMO
Nos últi mos anos, com a rápida expansão do plantio direto no Sul do Brasil, tem aumentado o interesse pela consorciação de plantas de cobertura de solo no outono/ínverno como fonte de $\mathbf{N}$ ao mi lho em sucessão. Para avaliar o efeito da aveia preta (AP) (Avena strigosa Schieb), da ervilhaca comum (EC) (Vicia sativa L.) e do nabo forrageiro (NF) (Raphanus sativus L. var. oleiferus Metzg.), em cultivos solteiros e consorciados, sobre o $\mathrm{N}$ acumulado e a produtividade de grãos de milho, foi realizado um experimento, no período de 1998 a 2000, na área experimental do Departamento de Solos da Universidade Federal de Santa Maria (RS), em um Argissolo Vermelho distrófico arênico (Hapludalf). O delineamento experimental foi de blocos inteiramente ao acaso com quatro repetições. Os tratamentos foram os seguintes: $100 \%$ AP (80 kg ha-1 de sementes), $100 \%$ EC $\left(80 \mathrm{~kg} \mathrm{ha}^{-1}\right), 100 \%$ NF $\left(14 \mathrm{~kg} \mathrm{ha}^{-1}\right), 15 \%$ AP $+85 \%$ EC, $30 \%$ AP $+70 \%$ EC, $45 \%$ AP $+55 \%$ EC, $15 \%$ AP $+85 \%$ NF e $30 \%$ AP + $70 \%$ NF. Além desses, foram utilizados dois tratamentos em pousio invernal onde cresceu a vegetação espontânea da área. Num tratamento sob pousio, o milho foi cultivado sem adubação nitrogenada e, no outro, o milho foi adubado com $180 \mathrm{~kg} \mathrm{ha}^{-1} \mathrm{de} \mathrm{N-}$ uréia. Foram avaliadas: a produção de matéria seca (MS), a concentração de $\mathbf{N}$ total do tecido vegetal do mi lho em di ferentes estádios de desenvol vi mento da cultura e a produtividade de grãos. A quantidade de $\mathbf{N}$ acumulado pelo mi lho e a produtividade de grãos em sucessão aos consórcios de aveia + ervilhaca não
\end{abstract}

\footnotetext{
(1) Parte da Tese de M estrado do primeiro autor, apresentada ao Programa de Pós-Graduação em Agronomia, U niversidade F ederal de Santa Maria - UFSM. Pesquisa parcialmente financiada com recursos da FAPERGS e do PRONEX-CNPq/FINEP. Recebido para publicação em novembro de 2001 e aprovado em junho de 2004.

(2) Doutorando do Programa de Pós-Graduação em Ciência do Solo, Universidade Federal de Santa Maria - UFSM. CEP 97105-900 Santa Maria (RS). Bolsistas da CAPES e CNPq. E-mail: sjgiacomini@mail.ufsm.br; andrepaulohubner@yahoo.com.br

(3) Professor Adjunto do Departamento de Solos, UFSM. E-mail: caita@ccr.ufsm.br

(4) Engenheiro-Agrônomo, MSc, Empresa de Pesquisa Agropecuária e Extensão Rural de Santa Catarina - EPAGRI. Rod. Admar Gonzaga 1347, Itacorubi, CE P 88034-901 Florianópolis (SC). E-mail: ivan-chiapinotto@epagri.rct-sc.br

(5) Mestrando do Programa de Pós-Graduação em Ciência do Solo, UFSM. E-mail; marceloagro@yahoo.com.br

(6) Aluno do Curso de Agronomia, UFSM.
} 


\begin{abstract}
diferiram da ervilhaca solteira e foram proporcionais à quantidade do $\mathbf{N}$ dos consórcios que estava presente na fitomassa da ervil haca. A ervilhaca e o nabo, tanto em culturas solteiras como consorciados à aveia, proporcionaram maior produtividade de milho do que após o pousio e a aveia solteira. Os resultados deste trabalho indicam que, consorciando aveia +ervilhaca, até uma proporção máxima de $\mathbf{3 0} \%$ de aveia, foi possível atingir uma produtividade de grãos de milho equivalente àquela da ervilhaca solteira e a $70 \%$ daquela obtida com o uso de $180 \mathrm{~kg} \mathrm{ha}^{-1}$ de $\mathrm{N}$-uréia no pousio.
\end{abstract}

Termos de indexação: adubação verde, recuperação de N, leguminosa/gramínea, Avena strigosa, Vicia sativa, Raphanus sativus.

SUMMARY: COVER CROP MIXTURES PRECEDING NO-TILL CORN. II -
NITROGEN ACCUMULATION BY CORN AND GRAIN YIELD

No-tillagehas been increasingly adopted by farmers in South Brazil and it has increased theinterest for themixtures of cover crops in theautumn/ winter as source of nitrogen to the corn in succession. A field experiment was carried out on a typic Hapludalf at the experimental area of theSoil ScienceDepartment, Federal U niversity of Santa M aria, Santa Maria, Rio Grande do Sul State, Brazil, in 1998/ 99 and 1999/ 00 to evaluate the effect of single crop and mixtures of black oat (BO) (Avena strigosa Schieb), common vetch (CV) (Vicia sativa L.) and oilseed radish (OR) (Raphanus sativus L. var. oleiferus M etzg.) on N accumulation and grain yield by corn. The experiment was set in a complete randomized block design with four replications. The treatments were: $100 \% \mathrm{BO}\left(80 \mathrm{~kg} \mathrm{ha}^{-1}\right.$ of seeds), $100 \%$ CV $\left(80 \mathrm{~kg} \mathrm{ha}^{-1}\right), 100 \%$ OR (14 kg ha-1), $15 \%$ BO + 85\% CV, $30 \%$ BO + $70 \%$ CV, $45 \% \mathrm{BO}+55 \% \mathrm{CV}, 15 \% \mathrm{BO}+85 \%$ OR and $30 \% \mathrm{BO}+70 \%$ OR. Two additional plots under winter fallow were also used for comparison. Other control treatments were corn cultivated without $\mathrm{N}$ fertilizer in oneplot and fertilized with $180 \mathrm{~kg} \mathrm{ha}^{-1}$ of $\mathrm{N}$-urea in another one Corn grain yiedd, dry matter and total $\mathrm{N}$ concentration in corn bi omass was evaluated at different crop stages. The amount of $\mathrm{N}$ accumulated by corn and the grain yield in succession of oat + vetch mixtures were not different from the single vetch, and were proportional to the $\mathrm{N}$ amount in the vetch biomass of the crop mixtures. Vetch and oilseed radish as singlecrop or in mixtures with black oat provided a higher corn grain yield than after fallow and single oat. Results of this study indicated that oat + vetch mixtures, up to a maximum proportion of $30 \%$ of oat, attained a productivity of corn grain equivalent to the singl evetch and $70 \%$ of that obtained with the use of $180 \mathrm{~kg} \mathrm{ha}^{-1}$ of $\mathrm{N}$-urea in the fallow.

Index terms: green manure, N recovery, legume, grass, Avena strigosa, Vicia sativa, Raphanus sativus.

\section{INTRODUÇÃO}

Na última década, o sistema plantio direto (SPD) apresentou forte expansão na região Sul do Brasil, tendo na aveia preta a princi pal cultura de cobertura no outono/inverno, antecedendo as culturas comerciais no verão. Todavia, nota-se um interesse crescente, especialmente por parte dos produtores de milho, em incluir no sistema de produção outras espécies, como a ervilhaca e o nabo forrageiro, com vistas em diminuir ouso de fertilizantes nitrogenados minerais na cultura. A capacidade dessas espécies em ciclar o $\mathrm{N}$ disponível do solo e, ou, de fixar o $\mathrm{N}_{2}$ atmosférico, a el evada demanda em $\mathrm{N}$ do milho e o al to custo dos fertilizantes nitrogenados são fatores que contribuem para a inclusão dessas espécies em rotação com o milho.
Alguns resultados obtidos indicam que a ervilhaca, em decorrência da sua capacidadeem fixar biologicamente o $\mathrm{N}_{2}$ atmosférico e da el evada taxa de decomposição dos resíduos culturais, é capaz de fornecer quantidades significativas de $\mathrm{N}$ ao milho em sucessão, proporcionando, em al guns casos, uma produtividade de grãos equivalente à adubação nitrogenada mineral (Heinrichs et al., 2001; Aita et al., 2001). J á a aveia, por acumular menor quantidade de $\mathrm{N}$ na fitomassa e liberá-lo lentamente após o seu manejo, afeta o fornecimento de $\mathrm{N}$ ea produtividade de grãos de milho (Aita et al., 2001).

U ma espécie de planta de cobertura de sol o cuja área cultivada tem aumentado significativamente no outono/inverno na região Sul do Brasil é a crucífera nabo forrageiro (Raphanus sativus $L$. var . ol eiferus Metzg.). Embora apresente maior taxa de 
decomposi ção eliberação de nutrientes dos resíduos culturais após o seu manejo em relação à aveia (Heinzmann, 1985), o nabo seassemelha à gramínea quanto à habilidade na absorção de $\mathrm{N}$ mineral do sol o eà produção de fitomassa (Derpsch et al., 1985). Resultados sobre o desempenho do nabo e do seu potencial em fornecer $\mathrm{N}$ às culturas em sucessão em solos arenosos com baixos teores de matéria orgânica são escassos (Basso \& Ceretta, 2000).

U ma alternativa que permitealiar as características desejáveis destas três espécies é a consorciação entre elas. Quando essa estratégia de cultivo envolver gramíneas e leguminosas, há uma combinação da maior habilidade das gramíneas em ciclar nutrientes com a capacidade das leguminosas em fixar o $\mathrm{N}_{2}$ atmosférico (Clark et al., 1997; Heinrichs et al., 2001), resultando numa fitomassa com relação $\mathrm{C} / \mathrm{N}$ intermediária àquela das culturas sol teiras (Clark et al., 1997; Amado et al., 2000), proporcionando, simultaneamente, proteção do solo e fornecimento de $\mathrm{N}$ à cultura em sucessão (Heinrichs et al., 2001).

São poucos os estudos que envolvem o consórcio entre plantas de cobertura do sol o no outono/inverno na regiãoSul do Brasil, restringindo-se ao consórcio entre aveia eervilhaca (Amado et al., 2000; Bortolini et al., 2000; Heinrichs et al., 2001). É necessário ampliar o número de espécies, bem como estabel ecer qual a proporção de cada espécie nos consórcios, a fim de maximizar o fornecimento de $\mathrm{N}$ ao milho. Praticamente, não existem informações na literatura brasileira sobre o padrão de acúmulo de $\mathrm{N}$ durante o cicl o do milho em sucessão a plantas de cobertura de solo no sistema plantio direto.

O presente estudo teve por objetivo avaliar o acúmulo de $\mathrm{N}$ e a produtividade de grãos de milho em sistema plantio direto, em sucessão à ervilhaca, ao nabo forrageiro e à aveia preta, cultivados isoladamente e consorciados.

\section{MATERIAL E MÉTODOS}

O trabalho foi realizado nos anos agrícolas de 1998/99, 1999/00 e 2000/01, na área experimental do Departamento de Sol os da Universidade F ederal de Santa Maria - RS. Ele faz parte de um projeto que visa mel horar a eficiência no uso de $\mathrm{N}$ pelo milho no sistema plantio direto, com o uso de plantas de cobertura, na região da Depressão Central do Rio Grande do Sul.

O local do experimento é constituído de um Argissolo Vermel ho distrófico arênico (Hapludalf), cujas características físico-químicas da camada 0$20 \mathrm{~cm}$, determinadas no início do experimento, conforme descrito em Tedesco et al. (1995), foram as seguintes: $150 \mathrm{~g} \mathrm{~kg}^{-1}$ de argila; $\mathrm{pH}_{\mathrm{H}_{2} \mathrm{O}}(1: 1)=5,5$; índice SMP $=6,2 ; 13,4 \mathrm{mg} \mathrm{dm}^{-3}$ deP e $57,5 \mathrm{mg} \mathrm{dm}^{-3}$ de $\mathrm{K}$ (extraídos por Mehlich 1); $0,0 \mathrm{cmol}_{\mathrm{c}} \mathrm{dm}^{-3}$ de $\mathrm{Al}^{3+}, 2,5 \mathrm{cmol}_{\mathrm{C}} \mathrm{dm}^{-3} \mathrm{deCa}^{2+} \mathrm{e} 0,8 \mathrm{cmol}_{\mathrm{C}} \mathrm{dm}^{-3} \mathrm{de} \mathrm{Mg}^{2+}$ (extraídos por $\mathrm{KCl} 1 \mathrm{~mol} \mathrm{~L}^{-1}$ ); $2,9 \mathrm{cmol}_{\mathrm{C}} \mathrm{dm}^{-3}$ de $\mathrm{H}+\mathrm{Al}$ e $16 \mathrm{~g} \mathrm{~kg}^{-1}$ de matéria orgânica.

O delineamento experimental utilizado foi o de blocos intei ramente ao acaso, com quatro repetições. Em parcelas de $5 \times 4 \mathrm{~m}$, foram semeadas três espécies de plantas de cobertura de sol o no outono/ inverno: ervilhaca comum (EC) (Vicia sativa L.), nabo forrageiro (NF) (Raphanus sativus L. var. ol eiferus M etzg.) e aveia preta (AP) (Avena strigosa Schieb) em culturas solteiras e consorciadas, compondo os seguintes tratamentos: $100 \%$ AP, $100 \%$ EC, $100 \% \mathrm{NF}, 15 \%$ AP + $85 \%$ EC, $30 \%$ AP $+70 \%$ EC, $45 \%$ AP + $55 \%$ EC (apenas em 1999/ 00), $15 \%$ AP + $85 \%$ NF (apenas em 1998/99) e $30 \%$ AP $+70 \% \mathrm{NF}$. Além desses, foram utilizados dois tratamentos em que o solo permaneceu em pousio invernal (vegetação espontânea da área). Num tratamento sob pousio, foram aplicados $180 \mathrm{~kg} \mathrm{ha}^{-1}$ de N-uréia na cultura do milho e, no outro, o milho foi cultivado sem adubação nitrogenada.

Os val ores de percentagem em cada tratamento representam as quantidades de sementes em $\mathrm{kg} \mathrm{ha}^{-1}$ utilizadas na semeadura de cada espécie. Nas culturas solteiras, utilizaram-se $80 \mathrm{~kg} \mathrm{ha}^{-1}$ de sementes para a aveia preta e ervilhaca comum e $14 \mathrm{~kg} \mathrm{ha}^{-1}$ para o nabo forrageiro.

A quantidade de $\mathrm{N}$ adicionado pela parte aérea das plantas de cobertura e pelas plantas invasoras no pousio invernal foi determinada a partir da avaliação da quantidade de matéria seca (MS) produzida (aos 130, 133 e 130 dias da semeadura das espécies, em 1998, 1999 e 2000, respectivamente) e da concentração de $\mathrm{N}$ do tecido vegetal. Foram coletadas aleatoriamente duas subamostras de $0,49 \mathrm{~m}^{2}$ em cada parcela, que logo foram reunidas em uma amostra composta. No momento da avaliação, a aveia encontrava-se no estádio de pleno florescimento, a ervilhaca no início do florescimento e o nabo forrageiro no final do florescimento. Nos tratamentos constituídos por consórcios, procedeuse à separação das espécies, a fim de determinar a contribuição de cada espécie na produção total de MS. O material col etado foi submetido à secagem a $65^{\circ} \mathrm{C}$ em estufa com circulação de ar até peso constante, pesado, moído em um triturador de forragens, subamostrado e moído novamente em moinho Willey equipado com peneira de 40 mesh.

Os teores de $\mathrm{N}$ total e $\mathrm{C}$ orgânico no tecido vegetal, seco emoído, foram determinados conforme Tedesco et al. (1995). As quantidades deN acumulado pelas plantas de cobertura e pela vegetação espontânea nos três anos, bem como a relação C/N da fitomassa das espécies, encontram-se no quadro 1.

O manejo das plantas de cobertura de outono/ inverno, efetuado 141, 146 e 137 dias após a semeadura, em 1998, 1999 e 2000, respectivamente, constou da apl icação do herbicida glifosate (960 g ha-1 
Quadro 1. Nitrogênio adicionado e relação C/N da fitomassa da parte aérea das plantas de cobertura nos três anos agrícolas

\begin{tabular}{|c|c|c|c|c|c|c|c|c|}
\hline \multirow{2}{*}{ Tratamento } & \multicolumn{4}{|c|}{ N adicionado(1) } & \multicolumn{4}{|c|}{ Relação C/N } \\
\hline & 1998/99 & 1999/00 & $2000 / 01$ & Média & 1998/99 & 1999/00 & $2000 / 01$ & Média \\
\hline & \multicolumn{4}{|c|}{$\mathrm{kg} \mathrm{ha}^{-1}$} & & & & \\
\hline $100 \% \mathrm{AP}^{(2)}$ & 59,0 & 56,9 & 42,1 & 52,7 & 34,2 & 32,5 & 42,9 & 36,5 \\
\hline $100 \% \mathrm{EC}$ & 112,8 & 91,1 & 62,6 & 88,8 & 12,8 & 13,7 & 15,8 & 14,1 \\
\hline $100 \% \mathrm{NF}$ & 101,7 & 66,7 & 63,2 & 77,2 & 22,4 & 22,5 & 25,5 & 23,5 \\
\hline $15 \% A P+85 \% E C$ & 98,9 & 88,8 & 72,0 & 86,6 & 25,2 & 16,2 & 22,6 & 21,3 \\
\hline $30 \% A P+70 \% E C$ & 83,8 & 85,5 & 73,5 & 80,9 & 23,9 & 17,0 & 22,6 & 21,2 \\
\hline $45 \% A P+55 \% E C$ & - & 87,4 & 85,6 & 86,5 & - & 18,6 & 23,6 & 21,1 \\
\hline $15 \% A P+85 \% N F$ & 95,9 & - & - & - & 23,2 & - & - & - \\
\hline $30 \% A P+70 \% N F$ & 104,9 & 66,8 & 54,6 & 75,4 & 22,3 & 23,4 & 31,7 & 25,8 \\
\hline Pousio(3) & 16,3 & 13,6 & 10,7 & 13,5 & 20,5 & 26,8 & 27,6 & 25,0 \\
\hline
\end{tabular}

(1) A adição de $\mathrm{N}$ pela ervilhaca quando consorciada à aveia na proporção de $85 \%$ foi de 34,74 e $54 \mathrm{~kg} \mathrm{ha}^{-1}$ de N e de 23 , 70 e 53 kg ha-1 de $\mathrm{N}$ na proporção de 70\% em 1998/99, 1999/00 e 2000/01, respectivamente. No consórcio com 55\% de ervilhaca, a leguminosa adicionou $63 \mathrm{~kg} \mathrm{ha}^{-1}$ de $\mathrm{N}$ em 1999/00 e $57 \mathrm{~kg} \mathrm{ha}^{-1}$ de $\mathrm{N}$ em 2000/01. ${ }^{(2)}$ AP = Aveia preta; $\mathrm{EC}=\mathrm{Ervilhaca}$ comum; NF = Nabo forrageiro. ${ }^{(3)} \mathrm{O}$ nitrogênio adicionado e a relação $\mathrm{C} / \mathrm{N}$ no tratamento em pousio referem-se à vegetação espontânea da área.

de i.a.) e posterior passagem do rolo faca. A semeadura do milho (Braskalb XL 212 em 1998/99, Cargil 901 em 1999/00 e Pioneer 32R21 em 2000/01) foi realizada sobre os resíduos culturais das plantas de cobertura de solo com semeadora para plantio direto, aos 10, 23 e 16 dias do manejo, em 1998/99, 1999/00 e 2000/01, respectivamente. O espaçamento entrelinhas foi de $0,9 \mathrm{~m}$, perfazendo uma população final de aproximadamente 55.000 plantas ha-1. Na semeadura, aplicou-se a mesma quantidade de $\mathrm{P}$ eK em todas as parcel as ( $30 \mathrm{~kg} \mathrm{ha}^{-1} \mathrm{deP}_{2} \mathrm{O}_{5}+70 \mathrm{~kg} \mathrm{ha}^{-1}$ de $_{2} \mathrm{O}$ em 1998/99 e $70 \mathrm{~kg} \mathrm{ha}^{-1}$ de $\mathrm{P}_{2} \mathrm{O}_{5}+100 \mathrm{~kg} \mathrm{ha}^{-1}$ de $_{2} \mathrm{O}$ em 1999/00 e 2000/01).

Notratamento com $180 \mathrm{~kg} \mathrm{ha}^{-1}$ de N-uréia, foram aplicados manual mente $30 \mathrm{~kg} \mathrm{ha}^{-1}$ de $\mathrm{N}$ logo após a semeadura do milho, na superfície do solo, próximo à linha de semeadura. O restante do $\mathrm{N}$ foi dividido em duas aplicações em cobertura de $65 \mathrm{~kg} \mathrm{ha}^{-1}$ de N, efetuadas manual mente a lanço, em toda a área das parcelas, 30 e 50 dias após a semeadura em 1998/99, 36 e 55 dias, em 1999/00, e 32 e 50 dias, em 2000/01. Todas as aplicações de $\mathrm{N}$-uréia foram efetuadas ao final do dia e, com exceção daquela realizada logo após a semeadura, em que o solo apresentava-se úmido, as demais foram seguidas de uma irrigação por aspersão, cuja quantidade d'água foi de aproximadamente $25 \mathrm{~mm}$.

A curva de acúmulo de $\mathrm{N}$ pelo milho foi determinada apenas nos dois primeiros anos, efetuando-se cinco col etas de plantas durante o ciclo da cultura em 1998/99 equatro em 1999/00, em sete dos nove tratamentos avaliados. Foram coletadas quatro plantas na área útil de cada parcela, cuja produção de MS foi obtida pela secagem em estufa a $65^{\circ} \mathrm{C}$ até massa constante. A concentração de Ntotal do tecido vegetal, previamente seco e moído, foi feita conforme Tedesco et al. (1995). Na última coleta de plantas de milho, realizada um e dez dias após a colheita de grãos, em 1998/99 e 1999/00, respectivamente, procedeu-se à separação dos diferentes componentes das plantas: grãos, palha da espiga, sabugo e parte aérea (colmos + folhas). A MS produzida e o $\mathrm{N}$ acumulado pelo milho representam a soma de todos os componentes. Em 2000/01, foi avaliado o acúmulo de N pelo milho apenas na fase de pleno florescimento da cultura (Quadro 2).

A estimativa da recuperação do $\mathrm{N}$ pel o milho nos tratamentos com plantas de cobertura e no tratamento com uréia foi feita a partir do acúmulo de $\mathrm{N}$ no florescimento e na colheita, nos dois primeiros anos, eapenas no florescimento, noúltimo ano. Para isso, as quantidades de $\mathrm{N}$ acumulado pelo milho nos tratamentos com plantas de cobertura e no tratamento em pousio com a aplicação de $180 \mathrm{~kg} \mathrm{ha}^{-1}$ de $\mathrm{N}$-uréia foram subtraídas da quantidade do $\mathrm{N}$ acumulado pelo milho no tratamento em pousio, sem a aplicação de N. E sse método mostra que o $\mathrm{N}$ das plantas de cobertura e o $\mathrm{N}$-uréia não influem na taxa de mineralização do N da matéria orgânica do solo. Todavia, existem resultados de pesquisa que mostram que a adição de materiais orgânicos estimula a população microbiana que pode acelerar a mineralização da matéria orgânica do solo (Kuzyakov et al., 2000). Caso isso tenha ocorrido no presente estudo, os valores estimados para a recuperação de $\mathrm{N}$ podem estar superestimados. Por isso, o valor resultante desta estimativa foi chamado de recuperação "aparente" do N aplicado, a qual foi calculada por meio da equação proposta por Mitchell \& Teel (1977):

$$
\text { RAN }=[(N T-N P) / N a p] \times 100
$$

em que 
Quadro 2. Cronograma das atividades realizadas nas plantas de cobertura e no mil ho, em cada ano agrícola

\begin{tabular}{lccc}
\hline Atividade & $\mathbf{1 9 9 8 / 9 9}$ & $\mathbf{1 9 9 9 / 0 0}$ & $\mathbf{2 0 0 0 / 0 1}$ \\
\hline & & Plantas de cobertura & \\
Manejo & $09 / 10 / 98$ & $11 / 10 / 99$ & \\
& & Milho & \\
& & $03 / 11 / 99$ & $23 / 10 / 00$ \\
Semeadura & $19 / 10 / 98$ & $06 / 12 / 99$ & $04 / 01 / 01^{(1)}$ \\
Coletas de plantas: & $10 / 11 / 98$ & $03 / 01 / 00$ & - \\
Coleta 1 & $20 / 11 / 98$ & $13 / 01 / 00(1)$ & - \\
Coleta 2 & $09 / 12 / 98$ & $20 / 03 / 00$ & - \\
Coleta 3 & $06 / 01 / 99(1)$ & - & $24 / 03 / 01$ \\
Coleta 4 & $19 / 03 / 99$ & $30 / 03 / 00$ & \\
Coleta 5 & $18 / 03 / 99$ & \multicolumn{2}{c}{} \\
Colheita de grãos & &
\end{tabular}

(1) Coleta de plantas de milho realizada na fase de pleno florescimento.

RAN = recuperação aparente do N aplicado;

$\mathrm{NT}$ = quantidade de $\mathrm{N}$ acumulado pelo milho nos tratamentos com plantas de cobertura, sem aplicação de $\mathrm{N}$, ou no pousio com a aplicação de $180 \mathrm{~kg} \mathrm{ha}^{-1}$ de $\mathrm{N}$;

$\mathrm{NP}=$ quantidade de $\mathrm{N}$ acumulado pelo milho no tratamento em pousio sem a aplicação de N ;

$\mathrm{NAp}=$ quantidade de $\mathrm{N}$ aplicado via uréia ou plantas de cobertura.

A produtividade de grãos de milho foi avaliada, coletando-se as plantas das quatro linhas centrais das subparcelas, desprezando-se 0,5 m em cada extremidade. Para expressar os resultados, determinou-sea umidade de grãos, corrigindo-a para $13 \%$.

Nos três anos, sempre que necessário, foram realizadas irrigações por aspersão durante o ciclo da cultura do milho, utilizando um sistema convencional com espaçamento entre aspersores de $12 \times 12$ m e uma taxa de aplicação de água de $8 \mathrm{~mm} \mathrm{~h}^{-1}$. No quadro 3, estão indicadas as precipitações pluviométricas mensais ocorridas desde o manejo das plantas de cobertura até a colheita do milho. O controle de ervas daninhas, nos três anos, foi feito pela aplicação da mistura dos herbicidas ametryne ( $2.000 \mathrm{~g} \mathrm{ha}^{-1}$ de i.a.) e nicosulfuron (40 $\mathrm{g}_{\text {ha-1 }}$ de i.a.) dez dias após a emergência do milho.

A análise estatística dos resultados relativos ao acúmulo de MS e de N e à produtividade de grãos foi feita separadamente para cada ano por meio da análise da variância, tendo sido as médias comparadas pel otestedeTukey a $5 \%$. Para os dados relativos às curvas de acúmulo de $\mathrm{N}$ e matéria seca de milho, compararam-seas médias de tratamentos em cada coleta realizada. Utilizou-se a análise de
Quadro 3. Preci pitação pluviométrica ocorrida no período entre o manejo das plantas de cobertura ea colheita do mi l ho nos anos agrícolas de 1998/ 99, 1999/00 e 2000/01 e precipitação normal (média de 1961 a 1990) ${ }^{(1)}$

\begin{tabular}{lrrrr}
\hline \multicolumn{1}{c}{ Mês } & $\mathbf{1 9 9 8 / 9 9}$ & $\mathbf{1 9 9 9 / 0 0}$ & $\mathbf{2 0 0 0 / 0 1}$ & Normal \\
\hline & \multicolumn{5}{c}{$\mathrm{mm}$} \\
\cline { 2 - 5 } & \multicolumn{4}{c}{ m } \\
Outubro & 123,7 & 208,6 & 185,0 & 145,9 \\
N ovembro & 99,5 & 83,1 & 204,2 & 132,2 \\
Dezembro & 114,3 & 75,2 & 154,2 & 133,5 \\
J aneiro & 110,7 & 246,0 & 309,9 & 145,1 \\
Fevereiro & 141,9 & 90,5 & 124,8 & 130,2 \\
Março & 82,4 & 248,9 & 144,1 & 151,7 \\
\hline
\end{tabular}

(1) I nformações obtidas na estação meteorológica da Universidade Federal de Santa Maria.

regressão linear simples para relacionar o $\mathrm{N}$ acumulado pel o mil ho com a relação $\mathrm{C} / \mathrm{N}$ das plantas de cobertura e com a proporção de semeadura de aveia e ervilhaca dos consórcios. Também foi relacionada a produtividade de grãos e o $\mathrm{N}$ acumulado pelo milho com a proporção do $\mathrm{N}$ do consórcio (aveia + ervilhaca) que estava presente na fitomassa da leguminosa.

\section{RESULTADOS E DISCUSSÃO}

\section{Nitrogênio acumulado pelo milho durante o ciclo da cultura}

Em todas as coletas de plantas de milho, realizadas nos tratamentos sem a aplicação de N 
mineral nos anos agrícolas 1998/99 e 1999/00, tanto a produção de MS da parte aérea (Figura 1 ) como o acúmulo de $\mathrm{N}$ pela cultura (Figura 2) não diferiram entre os tratamentos com aveia solteira e naquele em pousio. Tais resultados confirmam os obtidos em estudo paralelo, no qual a análise periódica da disponibilidade de $\mathrm{N}$ no solo não evidenciou a imobilização líquida de $\mathrm{N}$ durante a decomposição da palha da gramínea.

Os estudos referentes a plantas de cobertura de solo no sistema de produção de milho, em sua maioria, indicam que tanto a produção de MS como a quantidade de $\mathrm{N}$ acumulado pela cultura em sucessão a cereais no outono/inverno são menores do que no pousio. Sullivan et al. (1991), por exemplo, verificaram que o milho cultivado em sucessão ao

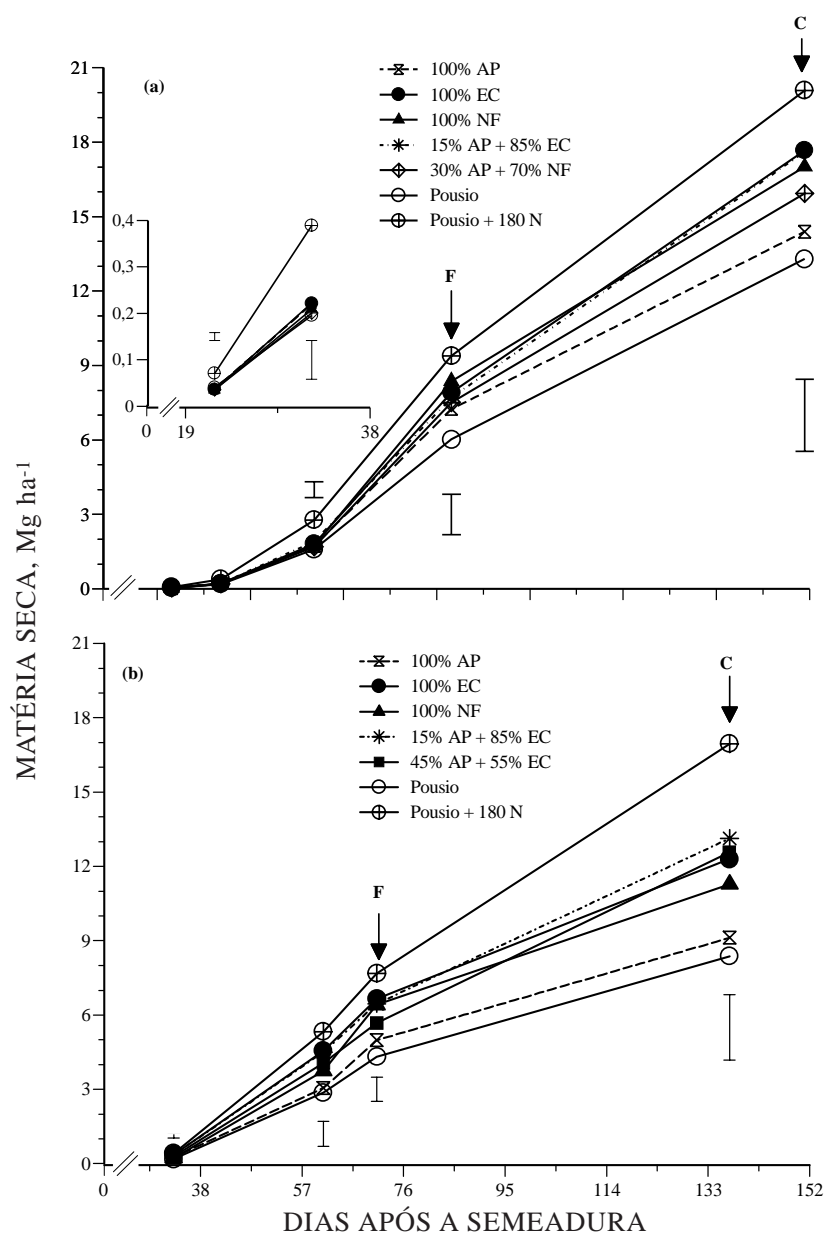

Figura 1. Produção de matéria seca pela parte aérea do milho durante o ciclo da cultura, nos anos agrícolas de 1998/99 (a) e 1999/00 (b). As barras verticais indicam a diferença mínima significativa (Tukey a $5 \%$ ). F e C indicam as coletas de plantas realizadas no estádio de florescimento pleno e na colheita, respectivamente. AP = Aveia preta; EC = Ervilhaca comum; NF = Nabo forrageiro. A figura menor, no detalhe, refere-se a uma ampliação do intervalo de 19 a 38 dias. centeio, em sistema plantio direto, acumulou menos $\mathrm{N}$ na fitomassa do que após leguminosas, atribuindo esse resultado à imobilização microbiana de $\mathrm{N}$ do solo de acordo com a quantidade de resíduos culturais de centeio $\left(6,5 \mathrm{Mg} \mathrm{ha}^{-1}\right)$ e com a elevada relação $C / N(C / N=59)$. É provável que o fato de nãoter si do detectada imobilização líquida de $\mathrm{N}$ após a aveia no presente estudo se deva à menor produção de MS dessa espécie (4,31 $\mathrm{Mg} \mathrm{ha}^{-1}$ na média dos três anos) e, principalmente, à menor $\mathrm{C} / \mathrm{N}$ dos seus resíduos culturais $(\mathrm{C} / \mathrm{N}=36,5)$ em relação ao trabalho de Sullivan et al. (1991).

Podem-se distinguir três grupos de tratamentos (F iguras 1 e 2). O primeiro, com os maiores valores de acúmulo de $\mathrm{N}$ e de produção de MS de milho, é aquele em que foram aplicados $180 \mathrm{~kg} \mathrm{ha}^{-1}$ de $\mathrm{N}$ no

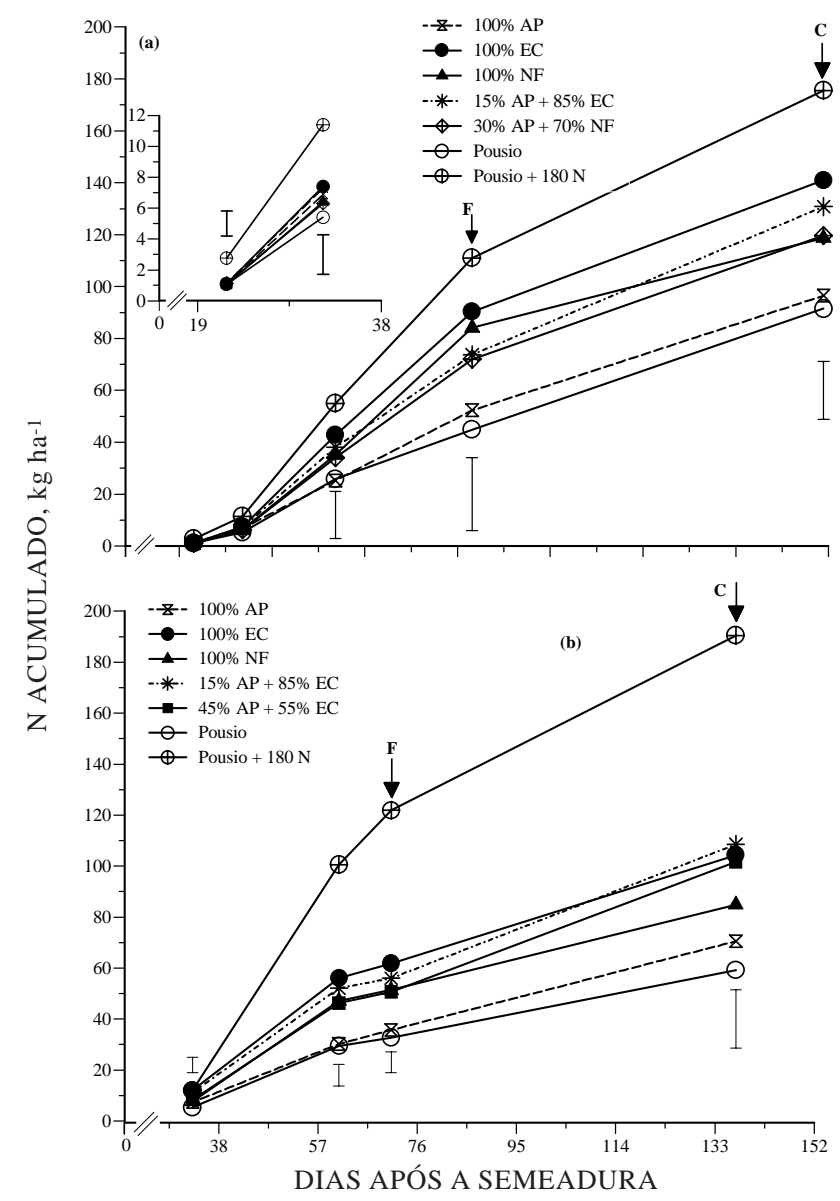

Figura 2. Acúmulo de nitrogênio pela parte aérea do milho durante o ciclo da cultura, nos anos agrícolas de 1998/99 (a) e 1999/00 (b). As barras verticais indicam a diferença mínima significativa (Tukey a $5 \%$ ). F e C indicam as coletas de plantas realizadas no estádio de florescimento pleno e na colheita, respectivamente. AP = Aveia preta; EC = Ervilhaca comum; NF = Nabo forrageiro. A figura menor, no detalhe, refere-se a uma ampliação do intervalo de 19 a 38 dias. 
pousio. Com valores intermediários aparecem os tratamentos com ervilhaca e nabo, em cultivos solteiros e consorciados à aveia. No terceiro grupo, com menores val ores para ambas as variáveis, estão os tratamentos com aveia solteira e pousio. Esses resultados coincidem com a maioria dos trabalhos em que o milho é cultivado em sucessão a plantas de cobertura. Aita et al. (1994) constataram que o milho cultivado após chícharo (Lathyrus sativus), tremoço azul (Lupinus angustifolius), ervilhaca comum e ervilha forrageira (Pisum arvense) acumulou, em média, $43 \%$ mais $\mathrm{N}$ na fitomassa da parteaérea do que quando cultivadoapós aveia preta.

Considerando o pequeno acúmulo deMS do milho nos primeiros 30 dias após a semeadura (Figura 1), também foi pequeno o acúmulo de $\mathrm{N}$ pela cultura nesse período (Figura 2). Na ausência de adubação nitrogenada, a quantidade de $\mathrm{N}$ acumulado pelo milho após ervilhaca solteira nesse período não diferiu significativamente do tratamento em pousio, tampouco dos demais tratamentos com plantas de cobertura em 1998/99 (Figura 2a, no detalhe), e superou o pousio em apenas $6,3 \mathrm{~kg} \mathrm{ha}^{-1}$ de $\mathrm{N}$ em 1999/00 (Figura 2b, no detalhe).

Apesar disso, constatou-se, em trabal ho paralelo a este, que 42 dias após o manejo das plantas de cobertura, a quantidade média de $\mathrm{N}$ mineral no solo da camada $0-90 \mathrm{~cm}$ no tratamento com ervilhaca solteira superou aquela encontrada no pousio em $55 \mathrm{~kg} \mathrm{ha}^{-1}$ de N mineral, em 1998/99, eem $37 \mathrm{~kg} \mathrm{ha}^{-1}$ de N mineral, em 1999/00. Esses resultados são semel hantes aos obtidos por Wagger (1989) eB ortolini et al. (2000), evidenciando a assincronia entre a liberação de $\mathrm{N}$ dos resíduos culturais da ervilhaca e a demanda em $\mathrm{N}$ do milho. O potencial de perdas desse $\mathrm{N}$ mineral por volatilização de amônia, denitrificação e, principalmente, por lixiviação de $\mathrm{N}-\mathrm{NO}_{3}{ }^{-}$reforça a importância de seguir a estratégia proposta por Heinzmann (1985) e Aita et al. (2001) de realizar a semeadura do milho o mais próximo possível do manejo das leguminosas.

Comparando o acúmulo de $\mathrm{N}$ pelo milho no tratamento em pousio com a aplicação de $180 \mathrm{~kg}$ ha-1 de $\mathrm{N}$-uréia e aquele encontrado após a ervilhaca solteira, observa-se que, em 1998/99, a diferença somente foi significativa em favor do pousio $+\mathrm{N}$-uréia na amostragem realizada na colheita (Figura 2a). No segundo ano, o tratamento com aplicação de Nuréia superou a leguminosa já a partir de 61 dias (F igura 2b). Tomando como exemplo a amostragem realizada no plenoflorescimento, observa-se que, em 1998/99, o milho após a ervilhaca sol teira acumulou o equivalente a $82 \%$ da quantidade de $\mathrm{N}$ acumulado com $180 \mathrm{~kg} \mathrm{ha}^{-1}$ de N-uréia (Figura 2a), contrastando com apenas $50 \%$ em 1999/00 (F igura 2b) e 53 \% em 2000/01 (dados não mostrados).

A melhor resposta do milho à aplicação de $\mathrm{N}$ mineral, em relação à ervilhaca, nos dois últimos anos, pode ser atribuída ao fato de ter sido a adição de $\mathrm{N}$ pela fitomassa da leguminosa solteira inferior à do primeiro ano. Observa-se (Quadro 1), que a quantidade de $\mathrm{N}$ adicionado ao sol o pela parte aérea da ervilhaca em 1999 e 2000 foi inferior àquela de 1998, em 19 e $44 \%$, respectivamente. Possíveis diferenças no aporte de $\mathrm{N}$ ao solo via sistema radicular da leguminosa não explicam tais resultados, já que apenas $7 \%$ da quantidade total do $\mathrm{N}$ adicionado pela ervilhaca foi encontrado nas raízes por Da Ros \& Aita (1996).

Vale destacar que as condições climáticas predominantes em cada anoe as possíveis diferenças entre os híbridos de milho utilizados, quanto à eficiência no aproveitamento do $\mathrm{N}$ disponível, também podem ter contribuído para esses resultados. Além disso, no segundo e no terceiro ano, a semeadura do milho foi feita 23 e 16 dias após o manejo das plantas de cobertura, respectivamente, enquanto, no primeiro ano, esse período foi de apenas 10 dias. Com o atraso na semeadura do milho, parte do $\mathrm{N}$ liberado da ervilhaca pode ter sido perdido por lixiviação, volatilização e, ou, denitrificação.

Um aspecto a ser evidenciado com base nos resultados dos dois últimos anos, quando foram comparados mais tratamentos envol vendo consórcio entre aveia e ervilhaca do que no primeiro ano, é que o aumento na proporção de aveia provocou uma diminuição na quantidade de $\mathrm{N}$ acumulado pelo milho na fase de florescimento da cultura (Figura 3). Para cada $1 \%$ de incremento na proporção de sementes de aveia houve uma diminuição no acúmulo de $\mathrm{N}$ pela parte aérea do milho de $0,217 \mathrm{~kg} \mathrm{ha}^{-1}$ de $\mathrm{N}$.

A partir desses resultados, pode-se inferir que o potencial de fornecimento de $\mathrm{N}$ ao milho pelos consórcios de aveia + ervilhaca é condicionado pela proporção do $\mathrm{N}$ total da fitomassa que é adicionado

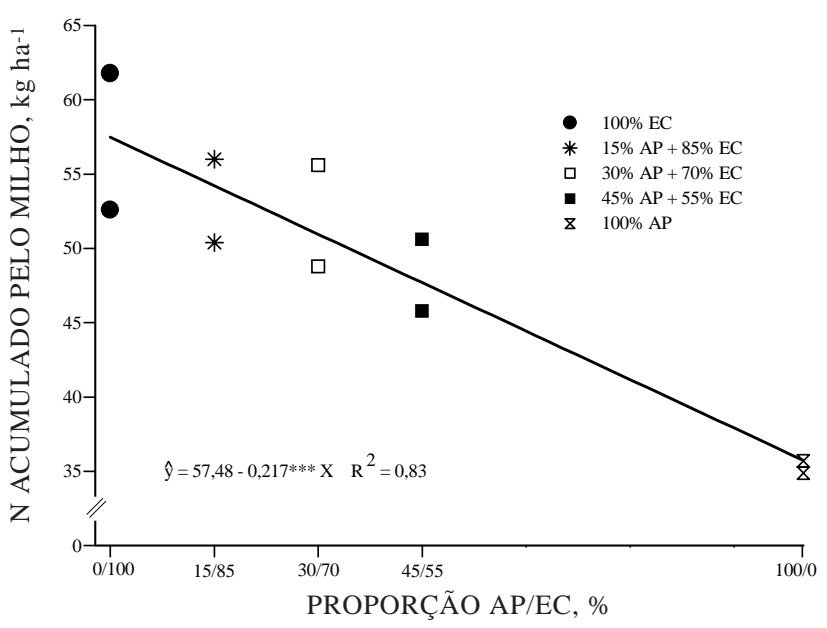

Figura 3. Relação entre a proporção de semeadura de ervilhaca comum (E C) e de aveia preta (AP) com a quantidade de $\mathbf{N}$ acumulado pelo milho no florescimento. *** Significativo a $0,1 \%$. 
por cada uma das espécies. Tomando como exemplo o ano de 1999/00 (Quadro 1), observa-se que, embora as quantidades totais de $\mathrm{N}$ adicionadas pela fitomassa dos tratamentos com ervilhaca solteira e nos consórcios com $15 \%$ AP $+85 \%$ EC e $45 \%$ $\mathrm{AP}+55 \% \mathrm{EC}$ tenham sido próximas $\left(91,1 \mathrm{~kg} \mathrm{ha}^{-1}\right.$ de $\mathrm{N}, 88,8 \mathrm{~kg} \mathrm{ha}^{-1}$ de $\mathrm{N}$ e $87,4 \mathrm{~kg} \mathrm{ha}^{-1}$ de $\mathrm{N}$, respectivamente), a participação da ervilhaca na quantidade total de $\mathrm{N}$ acumulado na fitomassa diminuiu de $91,1 \mathrm{~kg} \mathrm{ha}^{-1}$ de $\mathrm{N}$ quando em cultura solteira para $74 \mathrm{~kg} \mathrm{ha}^{-1}$ de N notratamento com $15 \%$ $\mathrm{AP}+85 \% \mathrm{EC}$ e para $63 \mathrm{~kg} \mathrm{ha}^{-1}$ de $\mathrm{N}$ no tratamento com $45 \%$ AP + $55 \%$ EC.

Confirmando resultados de outros autores (Wagger, 1989; Cantarella, 1993), os deste estudo mostram que, do $\mathrm{N}$ acumulado até à colheita do milho, 36 a 50 \% foi acumulado após oflorescimento da cultura.

O efeito da relação $\mathrm{C} / \mathrm{N}$ da fitomassa das plantas de cobertura sobre o acúmulo de $\mathrm{N}$ pelo milho no florescimento é evidenciado na figura 4, onde se observa que para cada unidade de aumento na relação C/N houve uma diminuição na quantidade de $\mathrm{N}$ acumulado pelo milho de $1,77 \mathrm{~kg} \mathrm{ha}^{-1}$ de $\mathrm{N}$, em 1998/99, e de 0,86 kg ha-1 deN na média de 1999/00 e 2000/01.

O N acumulado na fitomassa do nabo em 1998/ 99 e 1999/00 atingiu 90 e $73 \%$ do encontrado na ervilhaca em cultura solteira, respectivamente (Quadro 1). J á em 2000/01, o nabo acumulou tanto $\mathrm{N}$ quanto a ervilhaca. Todavia, convém destacar que, em decorrência do excesso de chuvas a partir do início do florescimento da ervilhaca em 2000/01, constatou-se visualmente a ocorrência de doenças com morte e queda precoce de muitas fol has. Esse

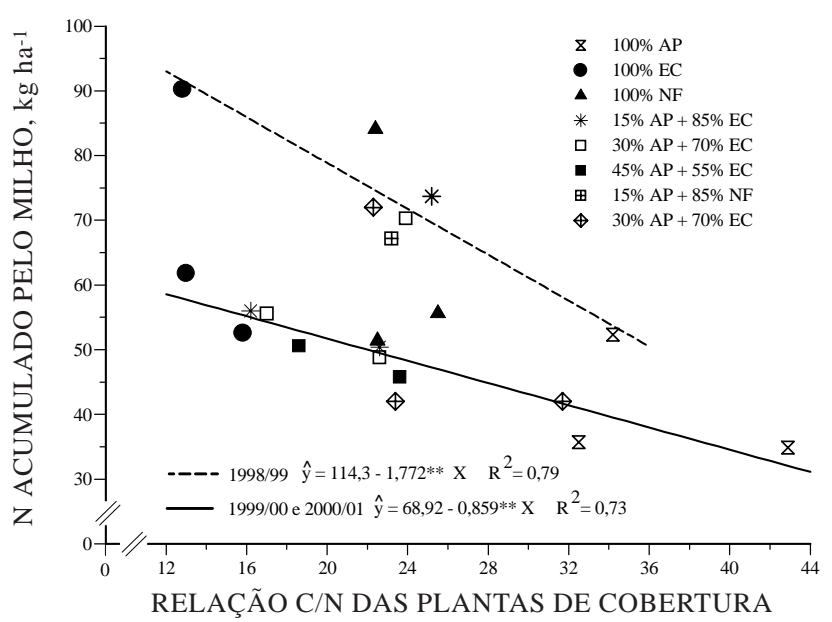

Figura 4. Relação entre a relação $\mathrm{C} / \mathrm{N}$ da fitomassa com a quantidade de $\mathbf{N}$ acumulado pelo milho no florescimento. AP = Aveia preta; $E C=$ Ervilhaca comum ; NF = Nabo forrageiro. **, *** Significativo a 1 e $0,1 \%$, respectivamente. problema ocorreu apenas na ervilhaca sol teira e deve ter contribuído para os baixos valores de $\mathrm{N}$ acumulado na espécie quando de sua col eta, na fase de florescimento pleno. Quanto ao acúmulo de N pel o milho em sucessão ao nabo, observa-se que, em 1998/99, ele não diferiu significativamente da ervilhaca solteira, embora, após a leguminosa, os valores tenham superado o nabo em 18, 7 e $16 \%$ nas amostragens realizadas aos 50 dias, 76 dias e na col heita do milho, respectivamente. No segundo ano, o milho acumulou 16, 16 e $19 \%$ a mais na ervilhaca do que no nabo aos 61 dias, 72 dias e na colheita, respectivamente. Essas quantidades de N acumulado pel o milho em sucessão ao nabo colocamno num patamar mais próximo da ervilhaca solteira do que da aveia solteira (Figura 2).

\section{Recuperação pelo milho do $\mathrm{N}$ adicionado pelas plantas de cobertura e pela uréia}

Analisando a recuperação aparente de $\mathrm{N}$ no florescimento do milho (Quadro 4), observa-se que, em sucessão aos tratamentos com plantas de cobertura, os valores obtidos em 1998/99 foram maiores do que os de 1999/00 e 2000/01. A menor recuperação do $\mathrm{N}$ adicionado pelas plantas de cobertura, nos dois últimos anos, podeser atribuída às elevadas precipitações na fase inicial da decomposição dos resíduos culturais das plantas de cobertura (Quadro 3), o que pode ter potencializado as perdas de $\mathrm{N}$ via lixiviação e, ou, denitrificação. Além disso, a maior demora na semeadura do milho após o manejo das plantas de cobertura nos dois últimos anos, conforme mencionado anteriormente, pode ter contribuído para aumentar as perdas de $\mathrm{N}$. O acúmul o gradativo de resíduos culturais de milho, com el evada relação $\mathrm{C} / \mathrm{N}$, também pode ter contribuído para diminuir a recuperação de $\mathrm{N}$ pelo milho, em decorrência de imobilização microbiana de $\mathrm{N}$ nos dois últimos anos. Possíveis diferenças na eficiência do aproveitamento do $\mathrm{N}$ pelos híbridos de milhoutilizados também não podem ser descartadas.

Comparando os tratamentos com plantas de cobertura em cultivo solteiro, observa-se que a recuperação de $\mathrm{N}$ pelo milho após ervilhaca e nabo superou a encontrada após a aveia (Quadro 4). Os val ores de recuperação de $\mathrm{N}$ pel o mil ho em sucessão à ervilhaca são próximos daquele obtido por Aita et al. (1994) e Almeida (2000) e mais el evados do que aquele obtido por Amado (1997) e, principalmente, por Da Ros (1993), que verificou ter o milho recuperado apenas $15 \%$ do $\mathrm{N}$ adicionado pela ervilhaca. Essas diferenças devem estar relacionadas principalmente com as condições climáticas predominantes em cada ano agrícola e com as características dos sol os empregados para o cultivo. Notrabalho de Da Ros (1993), por exemplo, o déficit hídrico ocorrido durante o ciclo da cultura do milho deve ter limitado a absorção de $\mathrm{N}$ pela cultura. 
Quadro 4. Recuperação aparente do $\mathbf{N}$ das plantas de cobertura e do $\mathbf{N}$-uréia pelo mi lho no florescimento e na colheita e produtividade de grãos de milho após plantas de cobertura e pousio invernal sem aplicação de $\mathbf{N}$ e após pousio invernal com a aplicação de $\mathbf{N}$-uréia, nos três anos de estudo

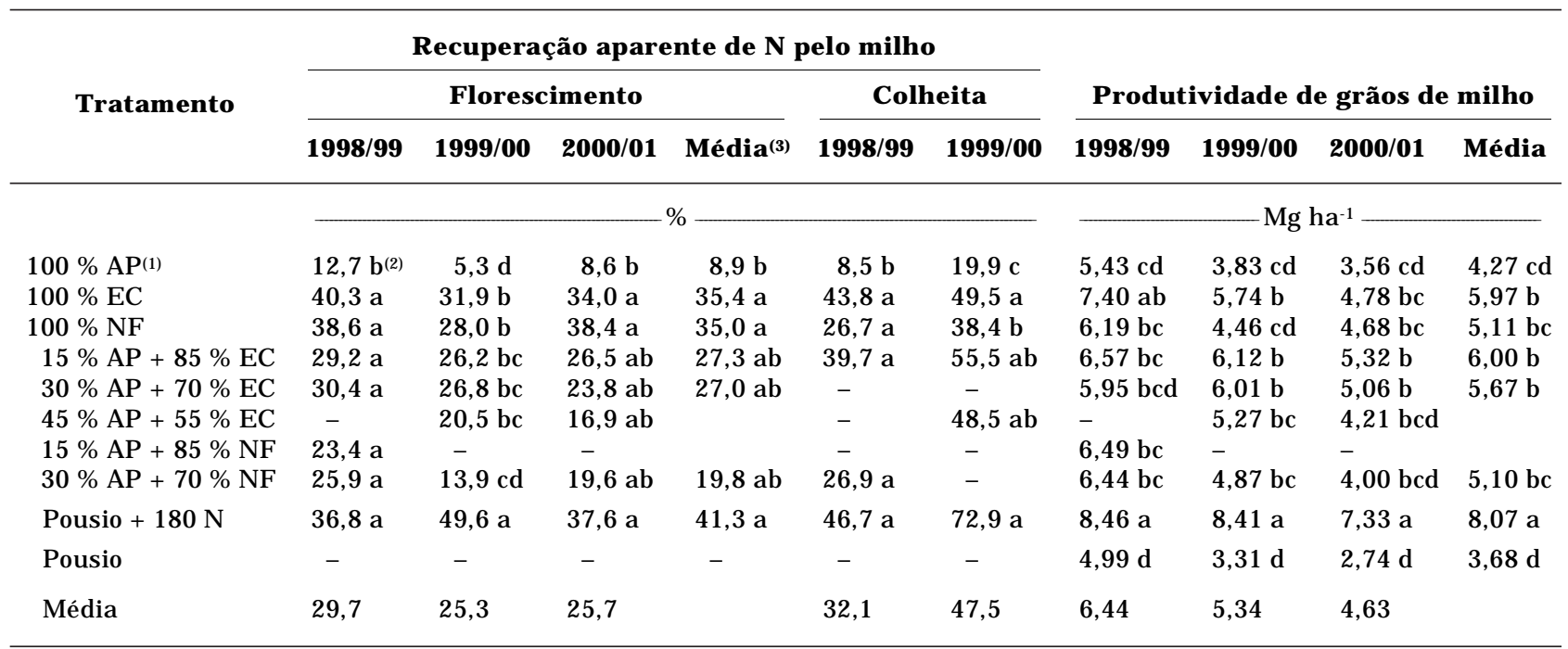

(1) AP =Aveia preta; $\mathrm{EC}=$ Ervilhaca comum ; NF = Nabo forrageiro. ${ }^{(2)}$ Médias seguidas de mesma letra na coluna, em cada ano, não

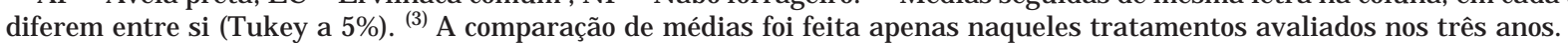

Embora as diferençasnãotenhamsidosignificativas, houve uma tendência de o milho recuperar menor quantidade de $\mathrm{N}$ com a inclusão da aveia nos consórcios com a ervilhaca. Observa-se que, em 1999/00, a recuperação de N pel o milho diminuiu de $31,9 \%$ na ervilhaca solteira para 20,5 no tratamento com maior proporção de aveia (45 \% AP + $55 \%$ EC) (Quadro 4). Comparando esses mesmos tratamentos em 2000/01, a diminuição foi de 34,0 \% para 16,9 \%. Tais resultados corroboram aqueles obtidos por Heinrichs (1996), em que a recuperação aparente de $\mathrm{N}$ pelo milho diminuiu de $36 \%$ na ervilhaca solteira para apenas $12 \%$ quando a leguminosa foi consorciada com $10 \%$ de aveia. Esta redução na recuperação de $\mathrm{N}$ devida à inclusão da gramínea nos consórcios deve estar relacionada com a menor liberação de $\mathrm{N}$ pelos consórcios e, ou, com a imobilização de N pela presença da aveia, haja vista que estes tratamentos adicionaram quantidades de $\mathrm{N}$ muito próximas à leguminosa sol teira (Quadro 1).

Com a recuperação aparente de $\mathrm{N}$, determinada próxima à colheita do milho, verificou-se que, principal mente em 1999/00, houve um aumento na eficiência de recuperação do $\mathrm{N}$ em relação àquela do pleno florescimento, independentemente da fonte de N (Quadro 4). Tomando o consórcio com $45 \%$ AP $+55 \%$ EC como exemplo, observou-se que a eficiência de recuperação de $\mathrm{N}$ aumentou de $20,5 \%$, no florescimento, para $48,5 \%$, na colheita, aproximando-se da ervilhaca sol teira quefoi de $49,5 \%$. Esse resultado revela que, a partir do florescimento, pode ter ocorrido remineralização de parte daquele $\mathrm{N}$ imobilizado na fase inicial da decomposição da aveia quando consorciada à ervilhaca.
Assim sendo, éfundamental que a dinâmica dos processos de imobilização/remineralização de N seja aval iada mais detal hadamenteem trabal hos futuros, tanto em incubações de laboratório, na ausência de plantas, como em condições de campo. A técnica da traçagem isotópica, com o uso de $\mathrm{N}$ marcado $\left({ }^{15} \mathrm{~N}\right)$ poderá contribuir para mel hor compreensão do ciclo interno do $\mathrm{N}$ no solo em trabalhos que envolvem plantas de cobertura de sol o, como propuseram Mary \& Recous (1994).

Quanto à adubação nitrogenada mineral, houve um aumento na eficiência de recuperação do $\mathrm{N}$ aplicado de $37,2 \%$, no florescimento, para $46,7 \%$, na colheita, em 1998/99, e de 49,6\% para 72,9\%, em 1999/00 (Quadro 4). Em trabalho realizado por Coelho et al. (1991) com o uso do isótopo ${ }^{15} \mathrm{~N}$, a recuperação de $\mathrm{N}$ pelo milho, avaliada na colheita, foi de $56 \%$ do N-uréia aplicado na dose de $60 \mathrm{~kg} \mathrm{ha}^{-1}$. J á Lara Cabezas et al. (2000), utilizando a mesma técnica e aplicando $100 \mathrm{~kg} \mathrm{ha}^{-1}$ de $\mathrm{N}$-uréia, encontraram uma recuperação de $\mathrm{N}$ em torno de $21 \%$. Essa baixa recuperação do $\mathrm{N}$ aplicado foi atribuída por esses autores a impedi mentos físi cos do sol o que limitaram o crescimento do sistema radicular em profundidade, bem como à el evada dose de $\mathrm{N}$ aplicada.

Os resultados relativos ao fornecimento de $\mathrm{N}$ mostram que a ervilhaca eo nabo, tanto em cultivos sol tei ros como consorciados à aveia, podem atender parcialmente à demanda de $\mathrm{N}$ do milho (Figura 2). É importante considerar que o efeito positivo das plantas de cobertura no fornecimento de $\mathrm{N}$ ao milho não deve ser atribuído exclusivamente ao $\mathrm{N}$ adicionado ao solo pela sua fitomassa. Para Bal dock 
et al. (1981), as plantas de cobertura podem afetar uma série de atributos do solo, tais como: a umidade, a temperatura, a aeração e o controle de pragas e moléstias ("efeito rotação"), com reflexos positivos sobre o acúmulo de $\mathrm{N}$ das culturas em sucessão.

\section{Produtividade de grãos}

A produtividade de grãos após aveia solteira e pousio sem aplicação de $\mathrm{N}$-uréia seguiu a mesma tendência observada para a produção de matéria seca e acúmulo de $\mathrm{N}$, não havendo diferenças entre esses dois tratamentos (Quadro 4). Este resultado confirma aquel es obtidos em estudo paral el o a este, em que, após aveia e pousio, a quantidade de $\mathrm{N}$ mineral do sol ofoi semel hante. Todavia, na mai oria dos trabal hos, quando a aveia antecede a cultura do milho, percebe-se redução na produtividade de grãos em relação ao cultivo do mil ho após pousio (Sulivan et al., 1991; Aita et al., 2001; Heinrichs et al., 2001), fato atribuído à diminuição na disponibilidade de $\mathrm{N}$ no solo pela imobilização microbiana.

Comparando a produtividade de grãos de milho dos tratamentos com ervilhaca solteira com aquela obtida após aveia solteira, observa-se que os val ores após a leguminosa superam a gramínea em $36 \%$ (1,97 $\left.\mathrm{Mg} \mathrm{ha}^{-1}\right), \quad 52 \%\left(1,91 \mathrm{Mg} \mathrm{ha}^{-1}\right)$ e $34 \%$ (1,22 $\left.\mathrm{Mg} \mathrm{ha}^{-1}\right)$, em 1998/99, 1999/00 e 2000/01, respectivamente (Quadro 4). Em relação ao pousio, o aumento na produtividade de grãos proporcionado pela ervilhaca foi de $48 \%$, em 1998/99, $73 \%$, em 1999/00, ede $74 \%$, em 2000/01. O efeito positivo da ervilhaca sobre a produtividade de grãos de milho é relatado em diversos trabalhos (Aita et al., 1994; Aita et al., 2001; Heinrichs et al., 2001) e deve-se ao N adicionado ao solo pela leguminosa, via fixação biológica de nitrogênio (FBN), eà facilidade com que esse $\mathrm{N}$ é liberado dos resíduos culturais durante a sua decomposição.

Quanto ao cultivo de mil ho em sucessão ao nabo solteiro, observa-se que a produtividade de grãos situou-se num nível intermediário ao da aveia e da ervilhaca sol teiras (Quadro 4). Na região Sul do Brasil, ainda é pequeno o número de estudos relativos à inclusão do nabo no sistema de produção de milho. No estado do Mato Grosso do Sul, Hernani et al. (1995) verificaram que a produtividade de milho em sucessão ao nabo foi equival ente àquel a dotratamento com ervilhaca peluda. J á Basso \& Ceretta (2000), trabalhando durante três anos em área próxima à do presente estudo e no mesmo tipo de solo, encontraram uma produtividade média de milho em sucessão ao nabo de 3,9 Mg ha-1 de grãos, sendo 37 \% inferior à do tratamento com consórcio de aveia +ervilhaca.

As produtividades de grãos de milho dos tratamentos com consórcio de aveia +ervilhaca edo tratamento com ervilhaca solteira não diferiram entresi (Quadro 4). Todavia, observa-seque, na média dos dois últimos anos, em que foram avaliados três consórcios entre aveia e ervilhaca, a produtividade de grãos nos tratamentos com $15 \%$ AP + 85 \% EC e
$30 \%$ AP $+70 \%$ EC superou aquela da ervilhaca solteira em 5,1 \% $\left(0,27 \mathrm{Mg} \mathrm{ha}^{-1}\right)$ e 8,7 \% $\left(0,46 \mathrm{Mg} \mathrm{ha}^{-1}\right)$, respectivamente. J á no tratamento com a maior proporção de aveia (45\% AP + $55 \%$ EC), o milho produziu, em média, $10,9 \%$ menos grãos $\left(0,52 \mathrm{Mg} \mathrm{ha}^{-1}\right)$ do queapós ervilhaca solteira. Esses resultados indicam que, consorciando aveia + ervilhaca até uma proporção de $30 \%$ de sementes deaveia, não há redução na produtividade de milho, em relação à ervilhaca solteira. No entanto, em ambas as situações, o $\mathrm{N}$ foi limitanteà produtividade do milho, visto que a cultura produziu menos nos tratamentos com plantas de cobertura do que no tratamento sob pousio, com a aplicação de $\mathrm{N}$-uréia.

Comparando a produtividade de grãos de milho em sucessão aos consórci os com $15 \%$ AP + $85 \%$ EC e $30 \% \mathrm{AP}+70 \% \mathrm{EC}$, comuns aos três anos de estudo, e em sucessão à ervilhaca sol teira, observase que, no primeiro ano, a produtividade média desses consórcios foi $15,4 \%\left(1,14 \mathrm{Mg} \mathrm{ha}^{-1}\right)$ inferior à de leguminosa solteira (Quadro 4). O pior desempenho do mil ho após os consórcios no primei ro ano, em relação aos dois anos seguintes, deve-se ao fato de que, em 1998/99, a maior parte do N acumulado pelos consórcios estava contido na fitomassa da gramínea (Quadro 1). Além disso, nos dois últimos anos, a quantidade de $\mathrm{N}$ adicionado ao solo pela leguminosa solteira foi menor do que no primeiro ano. Essas diferenças nas quantidades de $\mathrm{N}$ presente na fitomassa da aveia eervilhaca, quando consorciadas em diferentes proporções, afetam o acúmulo de $\mathrm{N}$ pelo milho, com reflexos na produtividade de grãos do milho em sucessão. A estreita relação entre o acúmulo de $\mathrm{N}$ e a produtividade de grãos de milho com o $\mathrm{N}$ dos consórcios que está contido na fitomassa da ervilhaca é mostrada na figura 5.

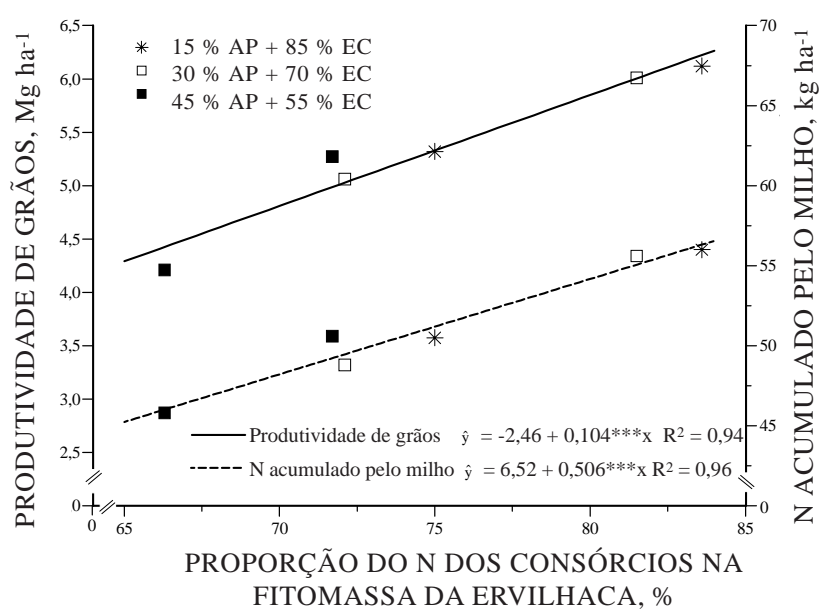

Figura 5. Relação entre a proporção do $\mathbf{N}$ do consórcio (aveia + ervilhaca) que está presente na fitomassa da ervilhaca com a produtividade de grãos e a quantidade de $\mathbf{N}$ acumulado pelo milho no florescimento. AP = Aveia preta; $\mathbf{E C}=$ Ervilhaca comum. *** Significativo a 0,1 \%. 
Nos três anos, a produtividade de grãos após a ervilhaca solteira superou aquel a do tratamento com aveia solteira. J á nos tratamentos com consórcio entre aveia eervilhaca, observa-se que, com exceção do primeiro ano, a produtividade de grãos foi maior do que aquela obtida após a aveia solteira (Quadro 4). Tais resultados evidenciam a importância da inclusão da leguminosa no consórcio com a gramínea, quando o objetivo for o fornecimento de $\mathrm{N}$ ao milho.

Os resultados deste estudo evidenciam que, consorciando aveia +ervilhaca, até uma proporção máxima de $30 \%$ de aveia, foi possível al cançar uma produtividade de grãos equivalente a $70 \%$ do teto máximo de produtividade obtido no pousio com a aplicação de $180 \mathrm{~kg} \mathrm{ha}^{-1}$ de N-uréia. As vantagens adicionais dos consórcios de aveia + ervilhaca e de aveia + nabo, em relação às culturas solteiras de ervilhaca e nabo, como a manutenção da umidade do sol o e a proteção deste contra a erosão pela maior persistência dos resíduos culturais da aveia após o manejo (Giacomini, 2001), evidenciam a importância dessa estratégia de cultivo entre plantas de cobertura de solo no outono/inverno com vistas na sustentabilidade na produção de milho, especialmente naqueles sol os com textura arenosa, com baixos teores de matéria orgânica e com baixa capacidade de suprimento de $\mathrm{N}$ à cultura. Um aspecto que merece avaliação na seqüência deste trabal ho envolve a comparação da viabilidade econômica entre o uso de N-uréia e de plantas de cobertura, em culturas sol teiras e consorciadas, como fonte de $\mathrm{N}$ ao milho.

\section{CONCLUSÕES}

1. Os consórcios de aveia +ervilhaca, até uma proporção máxima de $30 \%$ de sementes de aveia, proporcionam uma produtividade de grãos equivalente a $70 \%$ daquela obtida com o uso de $180 \mathrm{~kg} \mathrm{ha}^{-1}$ de N-uréia no pousio.

2. O N acumulado e a produtividade de grãos de milho em sucessão aos consórcios de aveia + ervilhaca são diretamente proporcionais à quantidade do $\mathrm{N}$ do consórcio que está presente na fitomassa da ervilhaca.

3. A ervilhaca e o nabo, tanto em culturas puras como consorciados à aveia, proporcionaram maior produtividade de milho em sucessão do que o pousio e aveia solteira.

4. $\mathrm{O}$ acúmulo reduzido de $\mathrm{N}$ pelo milho nos estádios iniciais da cultura demonstra que, para aumentar a eficiência no aproveitamento do $\mathrm{N}$ liberado dos resíduos culturais das plantas de cobertura, o cultivo do milho deve ser feito o mais próximo possível do manejo destas.

\section{LITERATURA CITADA}

AITA, C.; CERETTA, C.A.; THOMAS, A.L.; PAVINATO, A. \& BAYER, C. Espécies de inverno como fonte de nitrogênio para o milho no sistema de cultivo mínimo e feijão em plantio direto. R. Bras. Ci. Solo, 18:101-108, 1994.

AITA, C.; BASSO, C.J .; CERETTA, C.A.; GONÇALVES, C.N. \& DA ROS, C.O.C. Plantas de cobertura de solo como fontes denitrogênio ao milho. R. Bras. Ci. Solo, 25:157-1165, 2001.

ALMEIDA, A.C.R. Uso associado de esterco líquido de suínos e plantas de cobertura de solo na cultura do milho. Santa Maria, Universidade Federal de Santa Maria, 2000. 144p. (Tese de Mestrado)

AMADO, T.J.C. Disponibilidade de nitrogênio para o milho em sistemas de cultura e preparo de solo. Porto Alegre, Universidade Federal do Rio Grande do Sul, 1997. 201p. (Tese de Doutorado)

AMADO, T.J.C.; MIELNICZUK, J . \& FERNANDES, S.B.V. Leguminosas eadubação mineral como fontes de nitrogênio para o milho em sistemas de preparo do solo. R. Bras. Ci. Solo, 24:179-189, 2000.

BALDOCK, J .O.; HIGGS, R.L.; POUSON, W.H.; J AKOBS, J .A. \& SCHRADER, W.D. Legume and mineral $\mathrm{N}$ effects on crop yields in several crop sequences in the upper Mississipi Valley. Agron. J ., 73:885-890, 1981.

BASSO, C.J . \& CERETTA, C.A. Manejo do nitrogênio no milho em sucessão a plantas de cobertura de solo, sob plantio direto. R. Bras. Ci. Solo, 24:905-915, 2000.

BORTOLINI, C.G.; SILVA, P.R.F. \& ARGENTA, G. Sistemas consorciados de aveia preta e ervilhaca comum como cobertura de solo e seus efeitos na cultura do milho em sucessão. R. Bras. Ci. Solo, 24:897-903, 2000.

CANTARELLA, H. Calagem e adubação do milho. In: BULL, L.T. \& CANTARELLA, H., eds. Cultura do millho: fatores que afetam a produtividade. Piracicaba, POTAFOS, 1993. p.147-195.

CLARK, A.J .; DECKER, A.M.; MEISINGER, J J . \& MCINTOSH, M.S. Kill date of vetch, rye and a vetch-rye mixtures: I. Cover crop and corn nitrogen. Agron. J ., 89:427-434, 1997.

COELHO, A.M.; FRANÇA, G.E. \& BAHIA, A.F.C. Balanço de Nitrogênio $\left({ }^{15} \mathrm{~N}\right)$ em um Latossolo Vermel ho-Escuro sob vegetação de cerrado, cultivado com milho. R. Bras. Ci. Solo, 15:187-193, 1991.

DA ROS, C.O. Plantas de inverno para cobertura do solo e fornecimento de nitrogênio ao milho em plantio direto. Santa Maria, Universidade Federal de Santa Maria, 1993. 85p. (Tese de Mestrado)

DA ROS, C.O. \& AITA, C. Efeito de espécies de inverno na cobertura do solo e fornecimento de nitrogênio ao milho em plantio direto. R. Bras. Ci. Solo, 20:135-140, 1996.

DERPSCH, R.; SIDIRAS, N. \& HEINZMANN F.X. Manejo do sol o com coberturas verdes de inverno. Pesq. Agropec. Bras., 20:761-773, 1985. 
GIACOMINI, S.J . Consorciação de plantas de cobertura no outono/inverno e fornecimento de nitrogênio ao milho em sistema plantio direto. Santa Maria, Universidade Federal de Santa Maria, 2001. 124p. (Tese de Mestrado)

HEINRICHS, R.; AITA, C.; AMADO, T.J .C. \& FANCELLI, A.L. Cultivo consorciado de aveia e ervilhaca: relação $C / N$ da fitomassa e produtividade do milho em sucessão. R. Bras. Ci. Solo, 25:331-340, 2001.

HEINRICHS, R. Ervilhaca e aveia preta cultivadas simultaneamente como adubo verde e sua influência no rendimento do milho. Piracicaba, Escola Superior de Agricultura Luis de Queiroz, 1996. 65 p. (Tese de Mestrado)

HEINZMANN, F.X. Resíduos culturais de inverno eassimilação de nitrogênio por culturas de inverno. Pesq. Agropec. Bras., 20:1021-1030, 1985.

HERNANI, L.C.; ENDRES, V.C.; PITOL, C. \& SALTON, J.C. Adubos verdes de outono/inverno no Mato Grosso do Sul. Dourados, E mbrapa - Centro de Pesquisa de Agropecuária Oeste, 1995. 93p. (E mbrapa-CPAO documentos, 4).

KUZYAKOV, Y.; FRIEDEL, J.K. \& STAHR, K. Review of mechanisms and quantification of priming effects. Soil Biol. Biochem., 32:1485-1498, 2000.
LARA CABEZAS, W.A.R.; TRIVELIN, P.C.O.; KORNDÖRFER, G.H. \& PEREIRA, S. Balanço da adubação nitrogenada sólida efluida de cobertura na cultura do milho, em sistema plantio direto no triângulo mineiro (MG). R. Bras. Ci. Solo, 24:363-376, 2000.

MARY, B. \& RECOUS, S. Measurement of nitrogen mineralization and immobilization fluxes in soil as a means of predicting net mineralization. Europ. J . Agron., 3:291300, 1994.

MITCHELL, W.H. \& TEEL, M.R. Winter-annual cover crops for no-tillage corn production. Agron. J ., 69:569-573, 1977.

SULLIVAN, P.G.; PARRISH, D.J . \& LUNA, J .M. Cover crop contributions to $\mathrm{N}$ supply and water conservation in corn production. Am. J . Alter. Agric., 6:106-113, 1991.

TEDESCO, M.J .; GIANELLO, C.; BISSANI, C.A.; BOHNEN, H. \& VOLKWEISS, S.J. Análises de solo, plantas e outros materiais. Porto Alegre, Universidade Federal do Rio Grande do Sul, 1995. 174p. (Boletim Técnico, 5)

WAGGER, M.G. Cover crop management and nitrogen rate in relation to growth and yield of no-till corn. Agron. J ., 81:533538, 1989. 